\title{
Effect of differences in extubation timing on postoperative care following abdominal aortic replacement surgery: a comparison study
}

\author{
Naomi Ono, Junko Nakahira*, Toshiyuki Sawai, Yosuke Kuzukawa and Toshiaki Minami
}

\begin{abstract}
Background: Abdominal aortic replacement requires an extensive incision and strict blood pressure control, making rapid extubation of the tracheal tube and pain management difficult. The effects of extubation timing on the postoperative course and medical costs in the intensive care unit (ICU) were analyzed.

Methods: Patients who underwent elective abdominal aortic replacement were evaluated retrospectively. Patients were divided into those extubated on the day of surgery (Group A) and those extubated later (Group B). Group A was subdivided into extubation in the operating room (Group A1) or in the ICU (Group A2). Intubation time in the ICU, postoperative ICU stay, hospital stay, and total ICU expenses were compared among the four groups.

Results: Of the 191 patients, 95 were extubated on the day of surgery (Group A) and 96 later (Group B). The two groups differed in age and percutaneous coronary intervention history. Surgery and anesthesia durations, intraoperative infusion volume, and intraoperative bleeding amounts differed significantly in the two groups. Epidural anesthesia was given more frequently in Group A. Mean intubation time in the ICU $(2.6 \pm 2.8$ vs $17.4 \pm 5.1$ hours, $P<0.01)$, the ICU stay ( $2.1 \pm 0.3$ vs $2.4 \pm 0.8$ days, $P<0.01)$, and the hospital stay $(16.4 \pm 5.2$ vs $20.2 \pm 12.5$ days, $P=0.02$ ) were significantly shorter, and total ICU expenses were significantly lower $(1,036 \pm 307$ vs 1,565 $\pm 1,072$ dollars, $P<0.01)$, in Group A than in Group B. Of the 95 patients in Group A, 34 were extubated in the operating room (Group A1) and 61 in the ICU (Group A2). Arrhythmia, epidural anesthesia, and the amount of intraoperative infusion amount were significantly higher, and the percentage of women significantly lower, in Group A1 (vs Group A2). Postoperative ICU and hospital stays and the ICU costs were not significantly different.

Conclusion: Tracheal tube extubation on the day of abdominal aortic replacement surgery resulted in better postoperative course and lower costs than when extubation occurred later. Patients extubated in the operating room or the ICU on the day of surgery had similar postoperative courses and costs.
\end{abstract}

Keywords: Abdominal aortic replacement surgery, Timing of extubation, Cost in intensive care unit

\section{Background}

Abdominal aortic replacement surgery requires an extensive incision and strict control of blood pressure, making rapid extubation of the tracheal tube and pain management difficult. The use of anticoagulants makes it difficult to obtain patient informed consent of epidural anesthesia [1]. Following surgery, patients are admitted to an intensive care unit (ICU). If their postoperative course in the ICU is uneventful, they are moved to a ward.

* Correspondence: ane052@poh.osaka-med.ac.jp

Department of Anesthesiology, Osaka Medical College, 2-7 Daigaku-machi, Takatsuki, Osaka 569-8686, Japan
Proper timing of extubation of the tracheal tube after abdominal aortic replacement surgery may benefit patients and reduce the need for subsequent emergency surgery. This retrospective observational study was designed to evaluate the effects of the timing of extubation after postoperative ICU admission and later during the hospital stay, as well as the medical costs of the ICU length of stay (LOS).

\section{Methods}

After obtaining approval from the Ethics Committee of Osaka Medical College (approval number: 1234), data 
on patients who underwent abdominal aortic replacement surgery from January 2007 to December 2012 were reviewed retrospectively. Patients who underwent surgery with an aortic cross clamp under the renal arteries were included, whereas those who underwent emergency surgery or in whom an I-shaped graft was used were excluded.

All patients received general anesthesia and underwent epidural catheterization on the day before surgery. Epidural anesthesia was omitted in patients with a coagulopathy (international normalized ratio of prothrombin $>1.5$, partial thromboplastin time $>45$ seconds, platelet count $<100,000 / \mathrm{mm}^{3}$ ), those who took thrombolytic or anti-platelet drugs within 1 week before surgery, and those with myocardial ischemia. Epidural anesthesia was also not administered to patients with lumbar spine deformation, a history of lumbar or thoracic spine surgery, or numbness of the lower extremities due to lumbar or thoracic spine deformation. On the day before surgery, using an 18G Tuohy needle (Smith Medical, Tokyo, Japan), a catheter for epidural anesthesia was inserted into the epidural space at a site between Th8/9 and L1/2. Next, $3 \mathrm{ml}$ of 1\% mepivacaine was administered through the epidural catheter to confirm the abnormality. The epidural catheter was left in place for a maximum of 7 days.

General anesthesia was induced by inhalation of 3\% sevoflurane and intravenous administration of vecuronium $0.1 \mathrm{mg} / \mathrm{kg}$, fentanyl $0.1 \mathrm{mg} / \mathrm{kg}$, and propofol $1.5-2.0 \mathrm{mg} / \mathrm{kg}$. It was maintained by inhalation of sevoflurane and intravenous administration of rocuronium. Analgesia during surgery consisted of continuous intravenous administration of remifentanil $0.25-0.75 \mu \mathrm{g} / \mathrm{kg} / \mathrm{min}$ in patients without epidural anesthesia or continuous epidural administration of $0.375 \%$ ropivacaine $5 \mathrm{ml} / \mathrm{hr}$ in patients with epidural anesthesia. Throughout the operation, we monitored the patient's electrocardiogram, arterial pressure, central venous pressure (with an internal jugular vein catheter), percutaneous oxygen saturation, urine volume, capnography, and the bispectral index. Systolic blood pressure was adjusted to 75$90 \mathrm{mmHg}$ during surgery using intravenous remifentanil, alprostadil, nicardipine, and/or calcium, and/or by controlling the infusion volume. Before the aortic cross clamp was applied, intravenous heparin was administered to increase the activated clotting time to > 250 seconds. Blood transfusions were administered as necessary to maintain the hemoglobin concentration at $\geq 9.0 \mathrm{~g} / \mathrm{dl}$. Postoperative analgesia consisting of a continuous infusion of $0.2 \%$ ropivacaine $5 \mathrm{ml} / \mathrm{hr}$ in patients with epidural catheters or intravenous fentanyl $0.25-1.0 \mu \mathrm{g} / \mathrm{kg} / \mathrm{hr}$ to patients without epidural catheters, were administered until the patients were admitted to the wards. We did not use patient-controlled epidural anesthesia or patient-controlled IV infusions. Nor did we use a VAS (visual analog scale) to evaluate postoperative pain. Doctors working in the ICU manage pain with intravenous pain medicine and epidural anesthesia.

Tracheal extubation criteria included a response to verbal commands, body temperature $\geq 35.5^{\circ} \mathrm{C}$, arterial oxygen partial pressure $\geq 70 \mathrm{mmHg}$, arterial carbon dioxide partial pressure $<50 \mathrm{mmHg}$, and respiratory rate of 10-20 breaths/min in accordance with airway management guidelines at our institution. We did not monitor neuromuscular parameters. Beginning in January 2011, we began to use sugammadex for extubation in the operating room, although neostigmine was used for most patients. After the procedure, all patients were admitted to the ICU, with or without intubation.

Patients were divided into two groups, those extubated on the day of surgery (Group A) and those extubated on subsequent days (Group B). Patients in Group A were further subdivided into those extubated in the operating

Table 1 Baseline demographic and clinical characteristics of patients who underwent abdominal aortic replacement surgery and were extubated on the day of surgery (Group A) or on subsequent days (Group B)

\begin{tabular}{|c|c|c|c|}
\hline & $\begin{array}{l}\text { Group A } \\
(n=95)\end{array}$ & $\begin{array}{l}\text { Group B } \\
(n=96)\end{array}$ & $P$ value \\
\hline Age (years) & $69 \pm 9$ & $73 \pm 7$ & 0.004 \\
\hline Height (cm) & $164.4 \pm 7.8$ & $164.5 \pm 7.7$ & 0.939 \\
\hline Weight (kg) & $60.3 \pm 8.8$ & $62.9 \pm 12.5$ & 0.166 \\
\hline Female & $11(11.6 \%)$ & $12(12.5 \%)$ & 0.845 \\
\hline \multicolumn{4}{|l|}{ Medical history } \\
\hline Hypertension & $63(66.3 \%)$ & $73(76.0 \%)$ & 0.138 \\
\hline Diabetes mellitus & $20(21.1 \%)$ & $23(24.0 \%)$ & 0.631 \\
\hline Hyperlipidemia & $21(22.1 \%)$ & $26(27.1 \%)$ & 0.425 \\
\hline $\begin{array}{l}\text { Chronic obstructive } \\
\text { pulmonary disease }\end{array}$ & $7(7.4 \%)$ & $4(4.2 \%)$ & 0.372 \\
\hline Interstitial pneumonia & $1(1.1 \%)$ & $2(2.1 \%)$ & 1.000 \\
\hline Asthma & $4(4.2 \%)$ & $1(1.0 \%)$ & 0.211 \\
\hline Angina pectoris & $9(9.5 \%)$ & $16(16.7 \%)$ & 0.141 \\
\hline Previous cardiac surgery & $14(14.7 \%)$ & $16(16.7 \%)$ & 0.714 \\
\hline Coronary intervention & $15(15.8 \%)$ & $28(29.2 \%)$ & 0.027 \\
\hline Arrhythmia & $6(6.3 \%)$ & $7(7.3 \%)$ & 0.789 \\
\hline Cardiac disease & $2(2.1 \%)$ & $3(3.1 \%)$ & 1.000 \\
\hline Hemodialysis & $2(2.1 \%)$ & $1(1.0 \%)$ & 0.621 \\
\hline \multicolumn{4}{|l|}{ Medication } \\
\hline $\begin{array}{l}\text { Calcium channel } \\
\text { blocking agent }\end{array}$ & $45(47.4 \%)$ & $56(58.3 \%)$ & 0.129 \\
\hline$\beta$ receptor blocker & $17(17.9 \%)$ & $18(18.8 \%)$ & 0.879 \\
\hline ARB/ACEl & $43(45.3 \%)$ & $48(50.0 \%)$ & 0.512 \\
\hline Statin & $20(21.1 \%)$ & $21(21.9 \%)$ & 0.890 \\
\hline
\end{tabular}

Data are expressed as mean \pm standard deviation or as number (\%). Abbreviations: $A R B$ angiotensin II receptor blocker; $A C E I$ angiotensin-converting enzyme inhibitor. 
room (Group A1) and those extubated in the ICU (on the day of surgery) (Group A2). The postoperative ICU LOS, total medical expenses in the ICU, postoperative hospital LOS, death within 2 years, and postoperative complications were investigated and compared in Groups A and B and in Groups A1 and A2. Total medical expenses in the ICU included per-patient costs for blood tests, imaging, blood transfusion and infusion, and all other consumables (e.g., suction tubes, syringes). Total intubation time was defined as the time (in hours) from admission to the ICU to the time of extubation in the ICU. Patients extubated in the operating room had an intubation time of 0 hours.

Between-group comparisons were evaluated using the Mann-Whitney U-test, Student's t-test, Fisher's extact test, and the $X^{2}$ test, as applicable. A value of $\mathrm{P}<0.05$ was considered to indicate statistical significance. All analyses were performed using GraphPad Prism version 5.0 for Mac (GraphPad Software, San Diego, CA, USA).

\section{Results}

Of the 191 patients included in this study, one patient who was extubated in the ICU on the day of surgery died in hospital because of postoperative recurrent pneumonia. In addition, eight patients experienced pneumonia or atelectasis, three developed postoperative renal function disorders, one had postoperative ileus, and one had ischemic enteritis. One patient required surgery under general anesthesia to remove an arterial blood clot just after the abdominal aortic replacement surgery.

Of the 191 patients, 95 were extubated on the day of surgery (Group A) and 96 on subsequent days (Group B). Age and a medical history of percutaneous coronary intervention differed significantly in these two groups (Table 1).

Table 2 Postoperative outcomes in patients who underwent abdominal aortic replacement surgery and were extubated on the day of surgery (Group A) or on subsequent days (Group B)

\begin{tabular}{|c|c|c|c|}
\hline & Group A $(n=95)$ & Group B $(n=96)$ & $P$ value \\
\hline Operating time (min) & $271 \pm 60$ & $313 \pm 85$ & 0.001 \\
\hline Anesthetic time (min) & $378 \pm 61$ & $424 \pm 85$ & $<0.001$ \\
\hline \multicolumn{4}{|l|}{ Intraoperative parameters } \\
\hline Infusion volume (ml) & $4169 \pm 1125$ & $4908 \pm 1507$ & $<0.001$ \\
\hline Transfusion & $38(40.0 \%)$ & $48(50.0 \%)$ & 0.165 \\
\hline Urinary volume (ml) & $729 \pm 559$ & $741 \pm 551$ & 0.923 \\
\hline Amount of bleeding (ml) & $711 \pm 459$ & $900 \pm 641$ & 0.017 \\
\hline Mesenteric traction syndrome & $7(7.4 \%)$ & $14(14.6 \%)$ & 0.111 \\
\hline Final ACT & $147 \pm 18$ & $152 \pm 24$ & 0.280 \\
\hline Epidural anesthesia & $33(34.7 \%)$ & $12(12.5 \%)$ & $<0.001$ \\
\hline \multicolumn{4}{|l|}{ ICU-related parameters } \\
\hline Albumin volume & $177 \pm 379$ & $338 \pm 427$ & $<0.001$ \\
\hline Transfusion & $5(5.3 \%)$ & $12(12.5 \%)$ & 0.079 \\
\hline \multicolumn{4}{|l|}{ Postoperative complications } \\
\hline Respiratory disorders & $2(2.1 \%)$ & $8(8.3 \%)$ & 0.100 \\
\hline Renal dysfunction & $1(1.1 \%)$ & $2(2.1 \%)$ & 1.000 \\
\hline Cognitive dysfunction & $0(0.0 \%)$ & $1(1.0 \%)$ & 1.000 \\
\hline lleus & $0(0.0 \%)$ & $1(1.0 \%)$ & 1.000 \\
\hline Ischemic enteritis & $0(0.0 \%)$ & $1(1.0 \%)$ & 1.000 \\
\hline Thrombectomy & $1(1.1 \%)$ & $0(0.0 \%)$ & 0.497 \\
\hline In-hospital death & $1(1.1 \%)$ & $0(0.0 \%)$ & 0.479 \\
\hline Postoperative intubation time (hr) & $2.6 \pm 2.8$ & $17.4 \pm 5.1$ & $<0.001$ \\
\hline ICU stay (days) & $2.1 \pm 0.3$ & $2.4 \pm 0.8$ & $<0.001$ \\
\hline Postoperative hospital stay (days) & $16.4 \pm 5.2$ & $20.2 \pm 12.5$ & 0.017 \\
\hline Total expense in ICU (dollars) & $1,036 \pm 307$ & $1,565 \pm 1,072$ & $<0.001$ \\
\hline First day expense in ICU (dollars) & $637 \pm 37$ & $641 \pm 44$ & 0.012 \\
\hline Last day expanse in ICU (dollars) & $352 \pm 183$ & $422 \pm 213$ & 0.002 \\
\hline
\end{tabular}

Data were expressed as mean \pm standard deviation or as number (\%). Abbreviations: ACT activated clotting time; ICU intensive care unit. 
Analysis of intraoperative parameters showed significant between-group differences regarding the operating time, duration of anesthesia, intraoperative infusion volume, and amount of intraoperative bleeding. Group A patients were given epidural anesthesia more frequently than those in Group B. The mean intubation time in the ICU (2.6 \pm 2.8 vs $17.4 \pm 5.1$ hours, $\mathrm{P}<0.01)$, mean ICU LOS $(2.1 \pm 0.3$ vs $2.4 \pm 0.8$ days, $\mathrm{P}<0.01)$, and mean postoperative hospital LOS $(16.4 \pm 5.2$ vs $20.2 \pm 12.5$ days, $\mathrm{P}=0.02)$ were significantly shorter in Group A. Hospital stay exceeded 30 days in 10 patients because of a respiratory disorder, postoperative ileus, or ischemic enteritis. There were no complications associated with the epidural anesthesia and no major cardiovascular events, such as stroke or myocardial infarction. The total per-patient medical expenses in the ICU were significantly lower in Group A than in Group B $(1,036 \pm 307$ vs $1,565 \pm 1,072$ dollars; $\mathrm{P}<0.01$ ) (Table 2). We converted yen into US dollars at a rate of 113.6 yen per dollar.

Of the 95 patients extubated on the day of surgery, 34 were extubated in the operating room (Group A1) and
61 in the ICU (Group A2). The percentages of women and patients with arrhythmia were significantly higher in Group A2. Epidural anesthesia was performed more frequently in Group A1 than in Group A2. The intraoperative infusion volume was greater in Group A1 than in Group A2 (Table 3). There were no significant differences in postoperative care, including postoperative ICU LOS, hospital LOS, or ICU costs (Table 4).

\section{Discussion}

This retrospective study was designed to investigate the optimal timing of postoperative extubation in patients who underwent abdominal aortic replacement surgery, as shown by the postoperative ICU LOS, hospital LOS, and ICU costs. We found that the postoperative ICU LOS and hospital LOS were significantly shorter, and medical costs significantly lower, in patients extubated on the day of surgery than in those extubated later. There were no significant differences in the ICU expenses, postoperative ICU LOS, or hospital LOS, however, between patients extubated in the operating room

Table 3 Baseline demographic and clinical characteristics of patients who underwent abdominal aortic replacement surgery and were extubated on the day of surgery in the operating room (Group A1) or in the ICU (Group A2)

\begin{tabular}{|c|c|c|c|}
\hline & Group A1 $(n=34)$ & Group A2 $(n=61)$ & $P$ value \\
\hline Age (years) & $69 \pm 8$ & $69 \pm 10$ & 0.686 \\
\hline Height (cm) & $164.4 \pm 6.1$ & $164.4 \pm 8.6$ & 0.993 \\
\hline Weight (kg) & $61.1 \pm 8.6$ & $59.8 \pm 8.9$ & 0.510 \\
\hline Female & $0(0.0 \%)$ & $11(18.0 \%)$ & 0.007 \\
\hline \multicolumn{4}{|l|}{ Medical history } \\
\hline Hypertension & $21(61.8 \%)$ & $42(68.9 \%)$ & 0.484 \\
\hline Diabetes mellitus & $5(14.7 \%)$ & $15(24.6 \%)$ & 0.257 \\
\hline Hyperlipidemia & $7(20.6 \%)$ & $14(23.0 \%)$ & 0.790 \\
\hline Chronic obstructive pulmonary disease & $4(11.8 \%)$ & $3(4.9 \%)$ & 0.245 \\
\hline Interstitial pneumonia & $0(0.0 \%)$ & $1(1.6 \%)$ & 1.000 \\
\hline Asthma & $1(2.9 \%)$ & $3(4.9 \%)$ & 1.000 \\
\hline Angina pectoris & $5(14.7 \%)$ & $4(6.6 \%)$ & 0.274 \\
\hline Previous cardiac surgery & $3(8.8 \%)$ & $11(18.0 \%)$ & 0.366 \\
\hline Coronary intervention & $8(23.5 \%)$ & $7(11.5 \%)$ & 0.123 \\
\hline Smoking & $15(44.1 \%)$ & $26(42.6 \%)$ & 0.888 \\
\hline Arrhythmia & $5(14.7 \%)$ & $1(1.6 \%)$ & 0.021 \\
\hline Cardiac disease & $1(2.9 \%)$ & $1(1.6 \%)$ & 1.000 \\
\hline Hemodialysis & $0(0.0 \%)$ & $2(3.3 \%)$ & 0.536 \\
\hline \multicolumn{4}{|l|}{ Medication } \\
\hline Calcium channel blocking agent & $18(52.9 \%)$ & $27(44.3 \%)$ & 0.417 \\
\hline$\beta$ receptor blocker & $10(29.4 \%)$ & $7(11.5 \%)$ & 0.029 \\
\hline ARB/ACEI & $13(38.2 \%)$ & $30(49.2 \%)$ & 0.304 \\
\hline Statin & $7(20.6 \%)$ & $13(21.3 \%)$ & 0.934 \\
\hline
\end{tabular}

Data were expressed as mean \pm standard deviation or as number (\%).

Abbreviations: $A R B$ angiotensin II receptor blocker; $A C E I$ angiotensin-converting enzyme inhibitor; ICU intensive care unit. 
Table 4 Postoperative outcomes in patients who underwent abdominal aortic replacement surgery and were extubated on the day of surgery in the operating room (Group A1) or in the ICU (Group A2)

\begin{tabular}{|c|c|c|c|}
\hline & Group A1 $(n=34)$ & Group A2 $(n=61)$ & $P$ value \\
\hline Operating time (min) & $267 \pm 56$ & $274 \pm 63$ & 0.592 \\
\hline Anesthetic time (min) & $374 \pm 53$ & $380 \pm 66$ & 0.696 \\
\hline \multicolumn{4}{|l|}{ Intraoperative parameters } \\
\hline Infusion volume (ml) & $4512 \pm 1229$ & $3978 \pm 1023$ & 0.041 \\
\hline Transfusion & $16(47.1 \%)$ & $22(36.1 \%)$ & 0.294 \\
\hline Urinary volume (ml) & $839 \pm 642$ & $668 \pm 502$ & 0.319 \\
\hline Amount of bleeding (ml) & $699 \pm 481$ & $718 \pm 450$ & 0.698 \\
\hline Mesenteric traction syndrome & $2(5.9 \%)$ & $5(8.2 \%)$ & 1.000 \\
\hline Final ACT & $147 \pm 18$ & $148 \pm 18$ & 0.908 \\
\hline Epidural anesthesia & $17(50.0 \%)$ & $16(26.2 \%)$ & 0.020 \\
\hline \multicolumn{4}{|l|}{ ICU-related parameters } \\
\hline Albumin volume (ml) & $129 \pm 380$ & $203 \pm 379$ & 0.147 \\
\hline Transfusion & $1(2.9 \%)$ & $4(6.6 \%)$ & 0.652 \\
\hline \multicolumn{4}{|l|}{ Postoperative complications } \\
\hline Respiratory disorders & $0(0.0 \%)$ & $2(3.3 \%)$ & 0.536 \\
\hline Renal dysfunction & $1(2.9 \%)$ & $0(0.0 \%)$ & 0.358 \\
\hline Thrombectomy & $1(2.9 \%)$ & $0(0.0 \%)$ & 0.358 \\
\hline In-hospital death & $0(0.0 \%)$ & $1(1.6 \%)$ & 1.000 \\
\hline Postoperative intubation time (hr) & 0 & $4.0 \pm 2.6$ & NA \\
\hline ICU stay (days) & $2.0 \pm 0.2$ & $2.1 \pm 0.3$ & 0.647 \\
\hline Postoperative hospital stay (days) & $15.8 \pm 5.1$ & $16.7 \pm 5.3$ & 0.496 \\
\hline Total expense in ICU (dollars) & $1,003 \pm 272$ & $1,054 \pm 326$ & 0.813 \\
\hline First day expense in ICU (dollars) & $645 \pm 52$ & $633 \pm 23$ & 0.700 \\
\hline Last day expense in ICU (dollars) & $337 \pm 166$ & $361 \pm 193$ & 0.563 \\
\hline
\end{tabular}

Data were expressed as mean \pm standard deviation or as number (\%).

Abbreviations: $A C T$ activated clotting time; ICU intensive care unit.

and those extubated in the ICU on the day of surgery. These findings indicate that extubation on the day of surgery may benefit patients undergoing abdominal aortic replacement surgery by reducing medical expenses and the overall hospital LOS. Fewer female patients were extubated on the day of surgery because of differences between the sexes regarding the severity of the abdominal aortic aneurysm [2,3]. As has been reported elsewhere, female patients in this study who underwent this operation had more severe postoperative conditions than the male patients.

Epidural anesthesia was found to facilitate early postoperative extubation. In the present study, younger age and fewer interventions enabled the performance of epidural anesthesia, which in turn caused the anesthesiologists to extubate these patients earlier. A study of patients undergoing general surgery was unable to determine whether epidural anesthesia affected postoperative outcomes (e.g., the postoperative hospital LOS) [4,5], although epidural anesthesia has been reported to have an analgesic effect [6,7]. In addition, patient satisfaction was higher when epidural anesthesia was combined with general anesthesia [8]. Although the addition of epidural anesthesia has been found to provide a postoperative analgesic effect and to maintain postoperative respiratory function in patients undergoing abdominal aortic replacement surgery, it had no effect on patient outcomes $[9,10]$.

We found that the mean duration of maintaining epidural anesthesia was about 3 days, including the day of surgery. The effects of epidural analgesia in patients undergoing abdominal aortic replacement surgery have been reported to be significant only on the first day after surgery, with almost no effect on days 3-7 [11]. We therefore regarded removing the epidural catheter 3 days after surgery as appropriate.

Complications associated with epidural anesthesia are hematoma and infection. Because perioperative anticoagulation therapy is becoming more complicated, few patients who underwent abdominal aortic replacement 
surgery in our hospital in 2014 were given epidural anesthesia. Our postoperative goal for patients undergoing abdominal aortic replacement surgery is rapid extubation in the ICU, followed by an optimal analgesic method consisting of systemic analgesia and a peripheral nerve blocker.

We found that the amount of infusion was significantly greater in patients extubated later than on the day of surgery because they had had significantly longer anesthesia and operating times. The amount of the infusion, however, was greater in patients extubated in the operating room than in those extubated in the ICU on the day of surgery-despite there being no significant differences in their anesthesia or operative durations. However, a significantly higher percentage of patients extubated in the operating room had been given epidural anesthesia. The amount of the infusion was greater in these patients to prevent hypotension due to the blocked sympathetic system.

This study had several limitations. First, analysis on a case-by-case basis may have influenced our results, especially in regard to postoperative analgesia, because additional postoperative analgesia depended on evaluations by intensivists. Second, although this study included patients older than 70 years, we did not evaluate postoperative cognitive dysfunction because none of these patients required prolonged ICU stay due to postoperative cognitive dysfunction. Third, because the most important goal was to avoid fatal postoperative complications, the timing of the extubation tended to be longer. Fourth, we did not consider the effects of sugammadex, which was used in some cases for extubation in the operating room.

\section{Conclusions}

Extubation on the day of surgery was advantageous for patients as it reduced medical expenses and shortened the postoperative hospital LOS. Extubation in the operating room did not prove advantageous. Because epidural anesthesia could shorten the extubation time, alternative analgesic methods are required. Our study results recommend extubation in the ICU, especially on the day of surgery.

\section{Competing interests}

The authors declare that they have no competing interests.

\section{Authors' contributions}

NO participated in the design and coordination of the study and drafted the manuscript. JN made substantial contributions to the conception and design of the study and the acquisition of data and helped draft the manuscript and tables. TS performed the statistical analyses and revised the manuscript critically for important intellectual content. YK and TM made substantial contributions to the conception of the study and helped correct the manuscript. All authors read and approved the final manuscript.

Received: 26 December 2014 Accepted: 20 March 2015

Published online: 31 March 2015

\section{References}

1. Kawatani Y, Sugahara S, Kamiya I, Nakagaki T, Kira M, Kazama T. Report of an inquiry about epidural anesthesia for abdominal aortic aneurysm surgery in Japan. Masui. 2009;58:363-77.

2. Makrygiannis G, Courtois A, Drion P, Defraigne JO, Kuivaniemi H, Sakalihasan N. Sex differences in abdominal aortic aneurysm: the role of sex hormones. Ann Vasc Surg. 2014;28:1946-58.

3. Guetta V, Cannon 3rd RO. Cardiovascular effects of estrogen and lipid-lowering therapies in postmenopausal women. Circulation. 1996;93:1928-37.

4. Rigg JR, Jamrozik K, Myles PS, Silbert BS, Peyton PJ, Parsons RW, et al. Epidural anaesthesia and analgesia and outcome of major surgery: a randomised trial. Lancet. 2002;359:1276-82.

5. Peyton PJ, Myles PS, Silbert BS, Rigg JA, Jamrozik K, Parsons R. Perioperative epidural analgesia and outcome after major abdominal surgery in high-risk patients. Anesth Analg. 2003;96:548-54.

6. Jorgensen H, Wetterslev J, Moiniche S, Dahl JB. Epidural local anaesthetics versus opioid-based analgesic regimens on postoperative gastrointestinal paralysis, PONV and pain after abdominal surgery. Cochrane Database Syst Rev. 2000;4, CD001893.

7. Liu S, Carpenter RL, Neal JM. Epidural anesthesia and analgesia. Their role in postoperative outcome. Anesthesiology. 1995;82:1474-506.

8. Wu CL, Naqibuddin M, Fleisher LA. Measurement of patient satisfaction as an outcome of regional anesthesia and analgesia: a systematic review. Reg Anesth Pain Med. 2001;26:196-208.

9. Sen A, Erdivanli B, Özdemir A, Kazdal H, Tuğcugil E. Efficacy of continuous epidural analgesia versus total intravenous analgesia on postoperative pain control in endovascular abdominal aortic aneurysm repair: a retrospective case-control study. Biomed Res Int. 2014;2014:2051647.

10. Panaretou V, Toufektzian L, Siafaka I, Kouroukli I, Sigala F, Vlachopoulos C, et al. Postoperative pulmonary function after open abdominal aortic aneurysm repair in patients with chronic obstructive pulmonary disease: epidural versus intravenous analgesia. Ann Vasc Surg. 2012;26:149-55.

11. Park WY, Thompson JS, Lee KK. Effect of epidural anesthesia and analgesia on perioperative outcome: a randomized, controlled Veterans Affairs cooperative study. Ann Surg. 2001;234:560-9.

\section{Submit your next manuscript to BioMed Central and take full advantage of:}

- Convenient online submission

- Thorough peer review

- No space constraints or color figure charges

- Immediate publication on acceptance

- Inclusion in PubMed, CAS, Scopus and Google Scholar

- Research which is freely available for redistribution 